\section{SCIENTIFIC TREATMENT OF DELINQUENCY}

BY

EMANUEL MILLER, M.A., M.R.C.S., D.P.M.

CO-DIRECTOR, INSTITUTE FOR SCIENTIFIC TREATMENT OF DELINQUENCY ; PSYCHIATRIST, WEST END HOSPITAL FOR NERVOUS DISEASES : PHYSICIAN, INSTITUTE OF MEDICAL PSYCHOLOGY

\section{SCOPE AND PURPOSE OF THE INSTITUTE}

The importance of the medico-psychological approach to the study and treatment of delinquency is most clearly illustrated in the observation and treatment of the disorders of the child and the adolescent. The importance of this approach is twofold, inasmuch as it has led in the first place to many cures of juvenile delinquency, and in the second place, following from the first, it acts, or may act, prophylactically in diminishing the incidence of adult crime, for it has been found that adult criminals have been either delinquents in childhood or victims of ill-defined neurotic disorders. In fact, those who have studied closely the lives of adult criminals have found that in early childhood or in adolescence such persons presented the same psychological picture as juvenile delinquents do when their social and psychological states have been investigated.

The remarks that follow, which are arguments in favour of the psychological, medical, and social treatment of juvenile delinquency, are based upon personal experience of child and adolescent neurosis and delinquency gleaned in two clinics organized for this purpose and from treatment at the Institute for Scientific Treatment of Delinquency, and I should like to add that the larger number of the cases of $\mathrm{de}^{\prime}$ iquency were gathered from juvenile courts over a space of eight years, particularly from the children's court presided over by the late Sir William Clarke Hall, and latterly from other courts.

\section{The Juvenile Delinquent}

Observation of the procedure in the juvenile court has brought home to many of us, as physicians and psychiatrists, that the cases charged belong to many causal categories. Even from the very superficial data available to the court we have found that the causes of disordered behaviour and delinquency lay in various degrees and forms of ill-health, bad social conditions such as housing, overcrowding, and poor sanitation, locales of low moral level, broken families, and other broad social considerations. Amongst other causes which one regarded as more psychological than the above were the consequences of illegitimacy, drunkenness, and family disruption. Here again such apparently causal agencies could be attributed to some deeper causes, and these could only be estimated after careful investigation of family histories and the relationship of members of a family to one another. But over and above these determining conditions it is demonstrated from clinical experience that there are many cases which could only be elucidated by handling the individual child, with its personal psychological problems.

While the physician voluntarily attached to a juvenile court could, from time to time, make ad hoc suggestions to the magistrate as to the proper disposal of cases-that is to say, choice of a home or school suited to the particular temperament. of a child as superficially or hurriedly gauged in the court-the physician is driven to the conclusion that real help in reclaiming such children could only be hoped for if time were given for the closer investigation of the child in its social setting and, moreover, as an individual with a personal problem of which the delinquent act may have been but one manitestation. It is true that many cases charged with behaviour disorders and delinquency do not call for serious investigation; sometimes charges are exaggerated; parents alone may be at fault, and police officers unwisely shocked by behaviour which they would have condoned in their own children or in themselves when they were young. Such human interpretation of the occasion for delinquency and a charge may well be left, in a large number of cases, to the discretion of an understanding magistrate moved by compassion and a sense of humour.

\section{Value of Clinics: Illustrative Cases}

The value of these clinics lies in the fact that each case is investigated from the medical, the psychological, and the sociological point of view. Illustrative cases are the best evidence of the way in which the modern scientific investigation of delinquency can discover causes, and assign remedies for the cure or alleviation of delinquency.

For example, a boy was brought to the clinic for intermittent stealing and unmanageable temper. It was found, on medical investigation alone, that the child was suffering from a profound disease of nutrition with sugar hunger and other deficiencies which called for immediate correction. When suitable remedies were adopted, not only did the child's general health improve, but the irritable temper disappeared, and as long as the metabolic disturbance was under control the delinquencies did not occur.

In another boy, whose temper and bestial behaviour had reached such a pitch that the mother decided to charge him as being beyond control, the medical examination revealed an organic disease of the nervous system taking the form of a meningeal growth of naevoid form. In consequence of this discovery, the child has been disposed of, and has therefore been saved from segregation in an approved school, where he might have been handled as a delinquent until the obscure disorder was discovered.

A boy, aged 10, showed delinquent behaviour only when the family moved into a certain district notorious for its low morale. He was found to be intellectually retarded, but not defective in the statutory sense. The boy's record had been good before entering this district. As a result of these discoveries, we have been able to arrange for the family to move to a more stable milieu, and we have arranged for the boy's transfer to a school where his retarded intelligence can be dealt with on adequate educational lines. No further complaints have been brought against this lad since these changes have been achieved.

A boy, aged 11, had been adopted as the result of the death of his parents. He has since been guilty of stealing and of a variety of depraved practices. The foster-parents have, to all intents and purposes, dealt kindly with the lad, and one was obliged to conclude that the disordered behaviour was due to the child's mental attitude. He has been under prolonged individual psychological attention, with the result that many mental conflicts in his young mind have been cleared up and the disordered behaviour resulting from such mental disorder has diminished very appreciably.

These are but a few illustrations of the salvage work that can be carried out if juvenile delinquency is treated scientifically, making clear the causes-whether they be medical, psychological, or social-and dealing with them with the instruments at our disposal.

Of special interest has been the scientific treatment of the disorders of puberty and adolescence. This period is biologically a phase of storm and stress, during which many children are on the borderline of nervous breakdown or delinquency. It is essential that where conditions such as these have physiological as well as psychological causes, they should not be treated summarily by punitive measures, and even where the gravity of the disorder may call for segregation' in the interests of society, during such period of segregation every effort should be made to use a more benevolent, and incidently a more scientific, method of treating them.

\section{Results of Scientific Treatment}

Actual figures are perhaps the best means of graphically describing the value of treatment. In the course of two years at one clinic alone forty cases were referred from children's courts or from probation officers themselves. Had these cases not been referred to us one can estimate that thirty of them at least would ultimately have been admitted to approved schools, and it would be impossible to say what would have been the outcome of such form of treatment. Actually, however, only six cases out of the forty eventually entered approved schools. Treatment failed either because the child failed to co-operate and therefore broke his probation, or not sufficient time and latitude was allowed us to carry on with the case. 
The rest of these cases have remained more or less well and free from disorder. Some of them have been under continuous observation for a space of from two to two and a half years. This may seem a long time, but it is really a short period compared with the time spent at an industrial school, with a doubtful outcome at the end of the period. In many of these cases their whole demeanour has changed, and one has reason to believe that in some of them delinquent tendencies have been radically dealt with. At all events in all cases prolonged aftercare is maintained to study the psychological and social progress of each child in order finally to estimate the value of treatment.

Recoveries have been most striking in those cases that have been observed in and around puberty, for it has been discovered that in this period of stress the abnormal processes of mind and body are brought into relief, and psychological handling in most cases, and purely medical attention in a few others, have prevented the development of major disorders. There are some cases belonging to this period which have been followed up into early manhood and womanhood, and we have thus been able to see a delinquent tendency in the making, in action, and in the process of recovery.

\section{The Established Delinquent}

What is true of children and adolescents is true, if in a less degree, of adults of both sexes. While most psychologists and social workers realize that the established delinquent is not easy to handle, to keep to treatment, and to be economically and socially assisted, treatment has proved helpful and curative in many cases. An all too large number of. delinquents have made of crime a profession and therefore a means of living-if of living dangerously, an emotional incentive to crime which cannot be wholly ignored. These are the difficult cases and society must be protected from them, as it protects itself against small-pox by isolation. But the delinquents who realize that there is something wrong with them, or can be persuaded that freedom can be bought honourably by the quest for treatment honestly persevered in, these can and should be treated on the same lines as are the neuroses and borderline psychotics. In fact the records of the Institute for the Scientific Treatment of Delinquency show that the majority of delinquents referred suffer from anxiety symptoms, obsessional neuroses, compulsive thinking, which are closely related causally to the delinquency itself.

\section{Work of the Institute}

The Institute, which has now been working for three years; has a voluntary staff of four consultants and thirty psychotherapists with impeccable credentials and practical experience, who give consultations at the West End Hospital for Nervous Diseases to delinquents who present themselves voluntarily or who are referred by magistrates, judges, or probation officers. A social worker is now engaged who explores the social background of cases, and, where possible, social and economic stresses are relieved with the hope of diminishing the incentive to crime. Experience at the Institute and elsewhere proves that the intimate psychology of most delinquents is at fault, from character anomalies to psychosis, and each case deserves close investigation as a personal problem of body, mind, and social adaptation.

The Institute realizes that its work, while already productive of results, is experimental. It recognizes the value cf research in every soil from which crime presumably springs: psychopathology and psychiatry, sociology and economics, and anthropology.

For the ventilation of divergent views, and for the publication of researches, clinical and statistical, the Institute will shortly publish a scientific journal in which articles by distinguished workers and thinkers in many fields will appear. For some time it has embarked on educational work, and seminars for probation officers and social workers have been given. It is for medical men generally to give this work their close and sympathetic attention.

\section{INTERNATIONAL HOSPITAL ASSOCIATION}

\section{THE UNITED KINGDOM COUNCIL}

To give the International Hospital Association a live, representative character in this country, a national council has been set up. This council, "The United Kingdom Council of the International Hospital Association," includes three representatives of every association interested nationally in any aspect of hospital service. Associate members, of whom there is a growing body in Great Britain, will akso be represented. It is believed that an active council can do much to further the aims of the international organization, creating interest in its work and stressing its value to the public. Within the United Kingdom Council it can serve as a central unit, knitting together the separate hospital interests and forming a national bond between hospital associations, administrations, and others interested in the welfare and development of hospitals. The existence of a central organization provides facilities for the pooling of information and for the canalizing of policy and ideas in regard to affairs dealt with by the International Hospital Association.

The collection and publication of data in the different countries bearing upon various aspects of medicine, surgery, and hospital organization, plans of building, etc., need the establishment of an international bureau, and here the National Council can give much help. It can also make valuable contributions to the affairs of the International Hospital Association by its participation in the congresses, hospital study tours, and permanent study committees. Among the bodies that have expressed their desire to become members may be mentioned: the British Medical Association, the British Hospitals Association, the British Hospitals Contributory Schemes Association, the College of Nursing, the Royal Institute of British Architects, the Incorporated Association of Hospital Officers, the National Association of Local Government Officers, and the Pharmaceutical Society.
The council has been fortunate in the services it has received from individuals. To mention a few: Sir Harold Pink; chairman of council of the British Hospitals Association, Mr. R. H. P. Orde, honorary secretary of the British Hospitals Association, Mr. C. E. Elcock of the Royal Institute of British Architects, and Dr. Peter Macdonald, chairman of the Hospitals Committee of the British Medical Association, have been warm supporters of the council from the first.

\section{Study Tour in Czechoslovakia}

A hospital study tour, organized by the International Hospital Association and the Association of Czechoslovakian Hospitals, will take place from August 29th to September 15 th, and should be of great interest to all connected with hospital work and organization.

The tour is divided into two parts: Part I, from August 29 th to September 6th, will be a post-graduate course of lectures and visits; Part II, from September 6th to 14th, will be a study tour of the sanatoria of the High Tatra Mountains. Among the towns to be visited in the first part of the course are Carlsbad, Prague, Zlin, Brunn, and Moravská Ostrava. Visits of inspection will be paid to the Government Health Institute in Prague, the Masaryk Home in Krc, the Bata Hospital and Social Welfare Institution in Zlin, and the tuberculosis department of the Municipal Hospital of Bulovka. Lectures, to be given in the histological institute of the Charles University, Prague, will deal, among other subjects, with tuberculosis, rheumatism, mental and nervous complaints, carcinoma, diseases of the heart and circulation, and diseases of old age.

Comfortable travelling facilities by train and car are being provided, and suitable hotel accommodation has been arranged. Particulars of the tour and fares at party rates may be obtained from the Czechoslovakian Travel Bureau (Cedok), Ltd., 21, Regent Street, London, S.W.1, or from Thos. Cook and Sons, Ltd. 